\title{
The Role of Factor V Leiden 1691G>A and Prothrombin Gene 20210G>A Mutations in Hypercoagulable State Associated with Venous Thromboembolism among Sudanese Patients
}

\author{
Alfatih Aboalbasher Yousif ${ }^{1,2 *}$, Abdel Rahim Mahmmoud Muddathir ${ }^{1,3}$, Elwaleed Mohamed Elamin ${ }^{4}$ and Ahmed Alhadi ${ }^{5}$ \\ ${ }^{1}$ Department of Haematology and Blood Transfusion, Faculty of Medical Laboratory Sciences, University of Al Zaiem Al Azhari, Khartoum, Sudan \\ ${ }^{2}$ Department of Laboratory, Sinaw Hospital, Ministry of Health, Oman \\ ${ }^{3}$ Department of Clinical Laboratory Sciences, Faculty of Applied Medical Sciences, Taibah University, Almadina Almunawarah, Kingdom of Saudi Arabia \\ ${ }^{4}$ Department of Histopathology, Faculty of Medical Laboratory Sciences, University of Al Zaiem Al Azhari, Khartoum, Sudan \\ ${ }^{5}$ Department of Haematology, Faculty of Medical Laboratory Sciences, Sudan International University, Sudan
}

\begin{abstract}
Background: Factor V Leiden (FVL) 1691G>A and Prothrombin (PRT) 20210G $>A$ mutations are the most frequent hereditary cause of venous thrombosis in Caucasian and less frequency in African. The aim of this study was to detect the frequency of FVL $1691 \mathrm{G}>A$ and PRT 20210G $>A$ mutations among Sudanese venous thromboembolism (VTE) patients.
\end{abstract}

Material and Methods: This was descriptive Cross sectional study in which a total of 176 Sudanese subjects were enrolled in the period between July 2015 and July 2016. Among them, 38 apparently healthy Sudanese individuals as controls and 138 patients (47 males and 91 females), age range 18-90 with documented VTE confirmed by Duplex Doppler ultrasound at Khartoum Teaching Hospital and Sudan Heart Institute were included.

Result: In this study, the mean age was 48 years and $67 \%$ of total VTE patients were over the age of 40 years. Increased age was noted in the VTE patients with over $34 \%$ over the age of 60 years. The controlled subjects included significantly younger individual with $92.1 \%$ under the age of 50 and $81.5 \%$ under the age of 40 years. The FVL $1691 \mathrm{G}>\mathrm{A}$ and PRT 20210G $>A$ mutations were totally absent among the studied population.

Conclusion: The FVL 1619G>A and PRT 20210G>A mutations were totally absent among Sudanese VTE patients.

Keywords: Factor V Leiden; Prothrombin gene; Venous thromboembolism; Sudan

\section{Introduction}

Venous thromboembolic disease (VTE) is a term includes deep vein thrombosis (DVT) and pulmonary embolism (PE), or a combination of both. DVT is a common vascular condition that arises from the formation of a blood clot within the deep veins of the circulatory system. PE occurs when a segment of that thrombosis detaches or separates from the vein wall, travels through the bloodstream, and lodges in the pulmonary artery [1]. Venous thrombosis is a serious health problem causing significant morbidity and mortality. It may be fatal by its complication of pulmonary embolism Fatality rate of venous thrombosis is estimated at $1 \%$ to $2 \%[2,3]$. The pathogenesis of venous thrombosis is including acquired and genetic risks factors. Acquired risk factors including pregnancy, oral contraceptive use, estrogen therapy, obesity, malignancy, diabetic mellitus, immobility, trauma and post operation can precipitate thrombosis. Genetic risk factors include the deficiency of protein $\mathrm{C}$, protein $\mathrm{S}$, antithrombin and mutations of factor $\mathrm{V}$ Leiden and Prothrombin gene [4,5]. Both of these genetic abnormalities are commonly found in patients with VTE, with prevalence varying between $20 \%$ and $50 \%$ for factor V Leiden and between $5 \%$ and $19 \%$ for prothrombin gene mutation [6]. Previous research indicated that the presence of factor $\mathrm{V}$ mutation increases risk for venous thrombosis 7-fold in heterozygotes and 80-fold in homozygotes [7]. The incidence of venous thrombosis in homozygotes is almost $100 \%$ and $10 \%$ in heterozygotes.

Factor V Leiden Mutation $(1691 G>A)$ : A single point mutation $(\mathrm{G} \rightarrow \mathrm{A})$ at nucleotide position 1691 in the factor $V$ gene results in a mutant form of factor V known as factor V Leiden [8]. This mutation results in a replacement of Arginine residue 506 with a Glutamine (R506Q) at one of the factor $\mathrm{V}$ cleavage sites for activated protein C (APC). Mutant factor V is resistant to inactivation by APC [4]. Several studies have demonstrated a relationship between the presence of APC resistance and an increased risk of venous thrombosis [9]. The FV Leiden allele is associated with a hypercoagulable state, which is reflected by increased levels of prothrombin activation fragments in plasma of individuals with inherited APC resistance [10]. The hypercoagulable state in carriers of FV Leiden mutation is explained by two mechanisms; In the first one APC cleavage site in FVa is lost, which impairs the normal degradation of FVa by APC [11]. The second observation is that FV Leiden is a poor APC cofactor in the degradation of FVIIIa because the cleavage at Arg506 is required for expression of APC cofactor activity of FV [12-14]. Molecular detection of FVL mutation could be achieved by different methodologies, the most common among them is PCRRFLP [15].

The Factor II (Prothrombin) mutation $(20210 G>A)$ is the second most common genetic defect associated with inherited venous thrombosis. The genetic variation (Guanine to Adenine transition at position 20210) in the 3 '-untranslated region of the prothrombin gene had been associated with elevated blood levels of prothrombin which

*Corresponding author: Alfatih Aboalbasher Yousif, Ministry of Health Oman Sinaw Hospital, Postal code-400 Ibra, P.O, Box 275, Tel: +96893399058, +249912828387; Fax: +96825524693; E-mail: alfbadf@yahoo.com

Received June 08, 2017; Accepted August 10, 2017; Published August 15, 2017

Citation: Yousif AA, Muddathir ARM, Elamin EM, Alhadi A (2017) The Role of Factor V Leiden 1691G>A and Prothrombin Gene 20210G>A Mutations in Hypercoagulable State Associated with Venous Thromboembolism among Sudanese Patients. J Blood Disord Transfus 8: 386. doi: 10.4172/2155-9864.1000386

Copyright: $\odot 2017$ Yousif AA, et al. This is an open-access article distributed under the terms of the Creative Commons Attribution License, which permits unrestricted use, distribution, and reproduction in any medium, provided the original author and source are credited. 
Citation: Yousif AA, Muddathir ARM, Elamin EM, Alhadi A (2017) The Role of Factor V Leiden 1691G>A and Prothrombin Gene 20210G>A Mutations in Hypercoagulable State Associated with Venous Thromboembolism among Sudanese Patients. J Blood Disord Transfus 8: 386 . doi: 10.4172/2155-9864.1000386

Page 2 of 4

leads to a state of hypercoagulability, and increased incidence of venous thrombosis [5]. Some individuals who have Factor V Leiden mutation may also have the Prothrombin $20210 \mathrm{G}>A$ mutation. Women with prothrombin $20210 \mathrm{G}>A$ are at a 16 times greater risk of developing VTE if they use estrogen based birth control pills. It is also advised that women with this mutation avoid hormone replacement therapy $[16,17]$.

\section{Aim}

To determine the frequency of FVL $1691 G>A$ and PRT 20210G $>A$ mutations among Sudanese venous thromboembolism patients.

\section{Materials and Methods}

This was a descriptive, Cross sectional study, in which a total of 176 Sudanese subjects were enrolled in the period between July 2015 and July 2016. Among them, 138 patients (47 males and 91 females), age range 18-90 with clinical features of VTE confirmed by Duplex Doppler ultrasound at Khartoum Teaching Hospital and Sudan Heart Institute were included. Clinical data including age, sex, personal and family history for thromboembolic evidence, known risk factors for venous thromboembolism including surgery in the previous 3 months, child birth, pregnancy, malignancy and lengthy air travel (over 6 hours) were collected. The study included 38 apparently healthy Sudanese subjects as controls. Controls were free from history of venous thromboembolism, personal or family history of VTE, blood coagulation disorders, coagulation related medication and risk factors of VTE. The study was approved by the ethical committee of medical researches at $\mathrm{Al}$ Zaiem Al Azhari University. Informed consent was taken from participants before enrollment in this study.

\section{Statistical analysis}

All categorical variables were analyzed by descriptive statistics. Numerical variables were presented as Mean \pm SD.

\section{DNA extraction}

Genomic DNA was extracted from peripheral blood samples collected from patients and control using Aidlab Genomic extraction Kit (China) according to the manufacture protocol.

\section{PCR-RFLP for identification of FVL mutation}

G to A substitution at nucleotide 1691 which is located in exon 10 of factor $\mathrm{V}$ gene was determined by PCR-RFLP method and published primer sequence described by Nahid et al. [18].

Briefly; PCR was performed in $4 \mu \mathrm{l}$ premix tubes (iNtRON Biotechnology, Korea) in a total volume of $20 \mu \mathrm{l}$ containing $4 \mu \mathrm{l}$ genomic DNA, $10 \mu \mathrm{l}$ DNAase free DW 10 pico mol of each primer (Forward 5'TCAGGCAGGAACAACACCAT3' and Reverse 5'GGTTACTTCAAGGACAAAATACCTGTAAAGCT3'). Reactions were carried out in a thermal cycler (Eppendorf tube). Thermocycling profile consisted of $5 \mathrm{~min}$ at $94^{\circ} \mathrm{C}$ followed by 35 cycles including $94^{\circ} \mathrm{C}$ for $30 \mathrm{~s}, 57^{\circ} \mathrm{C}$ for $30 \mathrm{~s}$, and $72^{\circ} \mathrm{C}$ for $45 \mathrm{~s}$. Samples were maintained for final extension at $72^{\circ} \mathrm{C}$ for further $10 \mathrm{~min}$. PCR product was visualized by gel electrophoresis on $2 \%$ agarose gel (iNtRON Biotechnology, Korea) stained with Ethidium Bromide. Then $10 \mu \mathrm{l}$ of each PCR product was digested with 10 units of Hind III in NEB Buffer for 18 hours at $37^{\circ} \mathrm{C}$. Results of enzymatic digestion was separated by electrophoresis on $2 \%$ agarose gel (iNtRON Biotechnology, Korea) stained with Ethidium Bromide and the products were visualized in UV Transiluminator.

\section{PCR-RFLP for identification of Prothrombin gene $(20210 G>A)$ mutation}

G to A substitution at nucleotide 20210 which is located in exon
14 of factor II was examined by PCR-RFLP method. A region with 345 bp of exon 14 was amplified using following primers: Forward primer 5'TCTAGAAACAGTTGCCTGGC3' and Reverse primer 5'ATAGCACTGGGAGCATTGAAGC3' [18]. PCRs were performed in the same condition for factor $\mathrm{V}$ Leiden.

\section{Results}

The researcher describes characteristics of the samples and addresses the research questions. The data were collected for $138(65.9 \%$ females $34.1 \%$ males) with documented VTE, in this study. The mean age was 48 , age range of $18-90$, and $67 \%$ of total VTE patients were over the age of 40 years. Increased age was noted in the VTE patients with over $34 \%$ over the age of 60 years. The controlled subjects included significantly younger individual with $92.1 \%$ under the age of 50 and $81.5 \%$ under the age of 40 years. The variable frequencies of The past medical history for the overall participants included: without medical history $29 \%$, post-operative disease (POD) $23 \%$ post natal $16.7 \%$, hypertension (HTN) $5.8 \%$, pregnancy $5.8 \%$, thyroids disease $4.3 \%$, diabetes mellitus (DM) 4.3\%, malignancy $2.9 \%$, liver disease $2.2 \%$, cardiovascular disease (CVD) 2.2\%, sickle cells disease (SCD) 1.4, cerebrovascular accident (CVA) $0.7 \%$, respiratory disease $0.7 \%$ and systemic lupus erythrematosus (SLE) $0.7 \%$.

\section{PCR-RFLP for FVL $(1691 \mathrm{G}>\mathrm{A})$ gene mutation}

Amplification of a region of FV using the specified primers gave PCR products of $241 \mathrm{bp}$. In the normal gene there was no restriction site for Hind III in the 1691GG allele and the fragment of $241 \mathrm{bp}$ was remained undigested, whereas $1691 \mathrm{~A}$ allele was digested into two fragments of $209 \mathrm{bp}$ and $32 \mathrm{bp}$. Both patterns were detected when the subjects were heterozygous (1691GA). When the DNA sample contains the FVL mutation in homozygous form (1691 AA genotype), only 209 $\mathrm{bp}$ fragment will be present in the gel (complete digestion).

The FVL $1691 G>A$ mutation was not detected in this study population. Represented samples are shown in (Figure 1).

\section{PCR-RFLP for prothrombin $(20210 G>A)$ gene mutation}

Polymerase chain reaction for $20210 G>A$ gene yields a product sized $345 \mathrm{bp}$. In the normal gene there was no restriction site for Hind III in the 20210GG allele and fragment of 345 bp was remain undigested, whereas 20210AA allele was digested into two fragments of 322 and $23 \mathrm{bp}$. Both patterns were detected when subjects were heterozygous $(20210 G>A)$. When the DNA sample contains the prothrombin mutation in homozygous form (20210 AA, genotype), only $322 \mathrm{bp}$ fragment will be present in the gel (complete digestion).

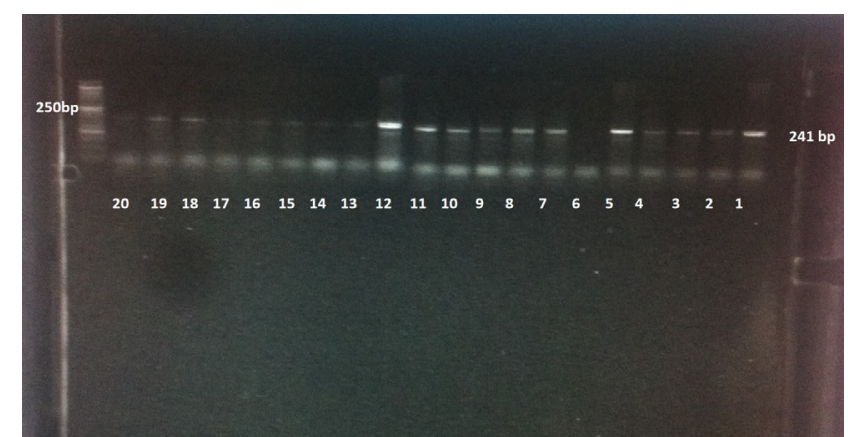

Figure 1: Shows Lane 21 is 50 bp DNA ladder. Lanes 1 up to 20: PCR products showing single band size $241 \mathrm{bp}$. 
Citation: Yousif AA, Muddathir ARM, Elamin EM, Alhadi A (2017) The Role of Factor V Leiden 1691G>A and Prothrombin Gene 20210G>A Mutations in Hypercoagulable State Associated with Venous Thromboembolism among Sudanese Patients. J Blood Disord Transfus 8: 386. doi: 10.4172/2155-9864.1000386

Page 3 of 4

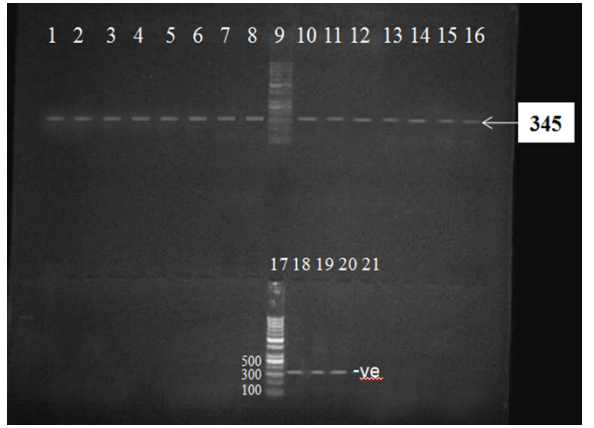

Figure 2: Shows representative $2 \%$ Agarose gel electrophoresis for PCR-RFLP of PRT mutation (20210 G>A). Lane 21: represents the negative control, lanes 1-20 except lanes 9, 17: represents the band size (345 bp) of PCR product lanes 9 and 17: represents 100 bp DNA ladder.

The PRT 20210G>A mutation was not detected in this study population.

Represented samples are shown in (Figure 2).

\section{Discussion}

The researchers determine the frequency of Prothrombin gene mutation and Factor V Leiden mutation in the Sudanese patients with venous thromboembolism.

Frequency of FVL varies from $0 \%$ to $15 \%$ according to ethnicity and geographic distribution worldwide [19]. FVL 1691G>A mutation is higher in Caucasian than Non-Caucasian. Low frequencies were reported in African, Asian and South European populations (0\%-3\%). It is relatively high in North America (5\%) and very high in Mediterranean populations (13.6\% in Syria, $12.3 \%$ in Jordan, and $13.4 \%$ in Greece) [20]. PRT 20210G $>A$ is the second most common thrombophilic polymorphism in Caucasians, associated with the risk of thrombosis with an estimated population frequency of $2-3 \%$ in healthy people and $6.2 \%$ in VTE patients [21]. In comparison with previous studies conducted by Mathonnet et al. and Jun et al. [22,23] had similar results in the frequency of factor V Leiden and Prothrombin gene mutation. Mathonnet et al., Jun et al. reported FVL and PRT gene mutations to be totally absent in Moroccan an and Chinese VTE patients [22,23]. The findings of this study are in complete agreement with previous study reported by Mathonnet et al. and Jun et al. [22,23]. In addition to that, the method of the study was done by using PCR followed by Hind III digestion was also similar to Mathonnet et al. and Jun et al. Margaglione et al. found higher rates of FVL $1691 G>A$ and PRT 20210G $>A$ in VTE patients and controlled (12.1\%), (7.1\%) respectively [24,25]. The data result in this study differs with the finding of Margaglione et al. [24] and these discrepancies are most probably due to the small sample size, non-equal distribution of patient's age, ethnic affiliation and different geographical prevalence of these mutations. In Sudan, factor V Leiden gene mutation and prothrombin 20210G $>A$ gene mutation are not associated with VTE in Sudanese patients.

\section{Conclusion}

The FV Leiden $1691 G>A$ and PRT 20210G $>A$ mutations were totally absent in Sudanese VTE patients.

\section{Conflict of Interest}

The authors declared that they have no conflict of interest.

\section{Author Contributions}

Alfatih, Abdel Rahim and Prof Elwaleed designed the study; Alfatih performed the research; Ahmed Alhadi analysed the data, and Alfatih and Abdel Rahim wrote the manuscript. All authors approved the final manuscript.

\section{Acknowledgements}

The authors thank the technologist at Khartoum Teaching Hospital Research and Laboratory Unit, Alneelin University molecular biology laboratory and Sudan Heart Center Laboratories for performing the laboratory tests and assisting with data collection.

\section{References}

1. Anderson FA Jr, Wheeler HB, Goldberg RJ, Hosmer DW, Patwardhan NA, et al. (1991) A population based perspective of the hospital incidence and case fatality rates of deep vein thrombosis and pulmonary embolism. The Worcester DVT study. Arch Int Med 151: 933-938.

2. Simone B, De Stefano V, Leoncini E, Zacho J, Martinelli I, et al. (2013) Risk of venous thromboembolism associated with single and combined effects of Factor V Leiden, Prothrombin 20210A and Methylenetethraydrofolate reductase C677T: A meta-analysis involving over 11,000 cases and 21,000 controls. Eur J Epidemiol 28: 621-647.

3. Saeed A, Sumreen, Kashif MA (2015) To determine the frequency of Factor Leiden in cases of deep vein thrombosis and healthy controls. Pak J Med Sci 31: 1219-1222.

4. Abu-Skeen IA, Mohamed AA, Moustafa NN, Badawy ME (2010) Factor V Leiden and prothrombin G20210A gene mutations in women with a history of thrombosis during pregnancy. Relation to pregnancy outcomes for mother and fetus. Saudi Med J 31: 123-129.

5. Poort RS, Rosendaal FR, Reitsma PH, Bertina RM (1996) A common genetic variation in the 3'-untranslated region of the prothrombin gene is associated with elevated plasma prothrombin levels and an increase in venous thrombosis. Blood 88: 3698-3703

6. Jadaon MM (2011) Epidemiology of activated protein C resistance and factor $v$ leiden mutation in the mediterranean region. Mediterr $\mathrm{J}$ Hematol Infect Dis 3: e2011037.

7. Bose P, Black S, Kadyrov M, Weissenborn U, Neulen J, et al. (2005) Heparin and aspirin attenuate placental apoptosis in vitro: implications for early pregnancy failure. Am J Obstet Gynecol 192: 23-30.

8. Chunilal SD, Bates SM (2009) Venous thromboembolism in pregnancy diagnosis, management and prevention. Thromb Haemost 101: 428-438.

9. Koster T, Rosendaal FR, de Ronde H, Briët E, Vandenbroucke JP, et al. (1993) Venous thrombosis due to poor anticoagulant response to activated protein $\mathrm{C}$ Leiden Thrombophilia Study. Lancet 342:1503-1506.

10. Rosendaal FR (1997) Risk factors for venous thrombosis: prevalence, risk, and interaction. Semin Hematol 34: 171-187.

11. Svensson PJ, Dahlbäck B (1994) Resistance to activated protein $C$ as a basis for venous thrombosis. N Engl J Med 330: 517-522.

12. Vandenbroucke JP, Koster T, Briët E, Reitsma PH, Bertina RM, et al. (1994) Increased risk of venous thrombosis in oral contraceptive users who are carriers of factor $\vee$ Leiden mutation. Lancet 344: 1453-1457.

13. Voorberg J, Roelse J, Koopman R, Büller H, Berends F, et al. (1994) Association of idiopathic venous thromboembolism with single point mutation at Arg506 of factor V. Lancet 343: 1535-1536.

14. Wake field TW, Myers DD, Henke PK (2008) Mechanisms of venous thrombosis and resolution. Arterioscler Thromb Vasc Biol 28: 387-391.

15. Provan D, Gribben JG (2010) Molecular hematology $3^{\text {rd }}$ edition. UK: Wiley Black Well.

16. Baklaja R, Pesic MC, Czarnecki J (2008) Hemostasis and hemorrhagic disorder 2nd edition. $\mathrm{GmbH}$ : Fermentation-Biotec.

17. Leroyer C, Mercier B, Oger E, Chenu E, Abgrall JF, et al. (1998) Prevalence of 20210. A allele of the prothrombin gene in venous thromboembolism patients Thromb Haemost 80: 49-51.

18. Nahid A, Maryam P, Shirin F (2012) Factor $V 1691 \mathrm{G}>A$ and prothrombin 20210G>A gene polymorphisms among Iranian patients with cerebral venous thrombosis. Neurology Asia 17: 199-203.

19. Montagnana M, Favaloro EJ, Franchini M, Guidi GC, Lippi G (2010) The role of ethnicity, age and gender in venous thromboembolism. J Thromb Thrombolysis 29: 489-496. 
Citation: Yousif AA, Muddathir ARM, Elamin EM, Alhadi A (2017) The Role of Factor V Leiden 1691G>A and Prothrombin Gene 20210G>A Mutations in Hypercoagulable State Associated with Venous Thromboembolism among Sudanese Patients. J Blood Disord Transfus 8: 386. doi: 10.4172/2155-9864.1000386

20. Geerts W, Cook D, Selby R, Etchells E (2002) Venous thromboembolism and its prevention in critical care. J Crit Care 17: 95-104.

21. Danckwardt S, Hartmann K, Gehring NH, Hentze MW, Kulozik AE (2006) 3 end processing of the prothrombin mRNA in thrombophilia. Acta Haematol 115: 192-197.

22. Mathonnet F, Nadifi S, Serazin-Leroy V, Dakouane M, Giudicelli Y (2002) Absence of factor $V$ Leiden mutation and low prothrombin G 20210 A mutation prevalence in a healthy Moroccan population. Thromb Haemost 88:1073-1074.

23. Jun ZJ, Ping T, Lei Y, Li L, Ming SY, et al. (2006) Prevalence of factor V Leiden and prothrombin G20210A mutations in Chinese patients with deep venous thrombosis and pulmonary embolism. Clin Lab Haematol 28: 111-116.

24. Margaglione M, Brancaccio V, De Lucia D, Martinelli I, Ciampa A, et al. (2000) Inherited thrombophilic risk factors and venous thromboembolism: distinct role in peripheral deep venous thrombosis and pulmonary embolism. Chest 118 : 1405-1411.
Citation: Yousif AA, Muddathir ARM, Elamin EM, Alhadi A (2017) The Role of Factor V Leiden 1691G>A and Prothrombin Gene 20210G>A Mutations in Hypercoagulable State Associated with Venous Thromboembolism among Sudanese Patients. J Blood Disord Transfus 8: 386. doi: 10.4172/2155 9864.1000386
OMICS International: Open Access Publication Benefits \&

\section{Features}

Unique features:

- Increased global visibility of articles through worldwide distribution and indexing

- Showcasing recent research output in a timely and updated manner

- Special issues on the current trends of scientific research

Special features:

- $700+$ Open Access Journals

$50,000+$ editorial team

Rapid review process

Quality and quick editorial, review and publication processing

Indexing at major indexing service

Sharing Option: Social Networking Enabled

Authors, Reviewers and Editors rewarded with online Scientific Credits

Better discount for your subsequent articles

Submit your manuscript at: http://www.omicsonline.org/submission/ 